Purnomo, K.; Kartamibardja, E.S. dan Satria, $H$.

\title{
PENENTUAN DAERAH RESERVAT PERIKANAN DI WADUK WADASLINTANG, JAWA TENGAH
}

\author{
Kunto Purnomo*), Endi Setiadi Kartamihardja*) dan Hendra Satria*)
}

\begin{abstract}
ABSTRAK
Penelitian pengelolaan sumber daya perikanan yang terdiri dari survei kualitas air, biologi dan dinamika populasi ikan di Waduk Wadaslintang, Jawa Tengah dilakukan untuk mengetahui kelayakan daerah-daerah calon reservat perikanan. Penelitian dilakukan pada bulan Juli, Agustus, September, November 1993 dan Januari 1994. Berdasarkan karakteristik biolimnologi dan struktur komunitas ikan terlihat bahwa daerah Brug, Pesanggrahan dan Kemejing layak untuk ditetapkan sebagai daerah reservat perikanan.
\end{abstract}

\section{ABSTRACT: Seloction of Fithery Conservation Areas in Vadadinteng Reservoir, Central Java, by Kunto Purnomo, Endi Setiadi Kartamibardja and Headra Satria.}

A study on the fishery management in Wadaslintang reservoir, Central Java was conducted to select fishery conservation areas. Based on the analysis of bio-limnological characteristics and fish community structure it can be concluded that waters of the village Brug, Pesanggrahan and Kemejing are suitable for fisheries conservation areas.

KEYWORDS: Reservat, manogement, bio-limmological characteristic, conservation area.

\section{PENDAHULUAN}

Pengelolaan sumber daya perikanan di waduk antara lain mencakup: manipulasi habitat, pengaturan populasi ikan dan penyediaan makanannya, serta pengaturan dan pengendalian sumber daya perikanannya sendiri (Bhukaswan, 1980). Teknologi konservasi adalah salah satu teknik perlindungan dan manipulasi populasi ikan yang didasarkan atas studi tentang ekologi perairan, biologi dan dinamika populasi ikan. Penerapannya selain berguna dalam konservasi dan pemanfaatan plasma nutfah, juga berguna dalam menjaga keseimbangan populasi ikan dan kelestarian sumber daya.

Waduk Wadaslintang di Kabupaten Banjarnegara, Jawa Tengah, luasnya 1.400 ha dengan kedalaman maksimum $90 \mathrm{~m}$. Sebagai waduk yang relatif masih baru tetapi tingkat pemanfaatannya sudah tinggi maka diperlukan suatu upaya untuk mempertahankan keragaman dan populasi ikan yang ada agar tidak punah atau menurun. Menurut Kartamihardja (1992), di waduk ini pernah ditemukan ikan Puntius orphroides dalam kelimpahan yang banyak dan belum

Teneliti pada Instalasi Penelitian Perikanan Air Tawar Jatiluhur, Purwakarta 
pernah dijumpai di waduk yang lain sehingga perlu dijaga kelestariannya melalui upaya pembuatan reservat. Untuk menentukan daerah yang sesuai bagi lokasi reservat diperlukan pengumpulan informasi tentang karakteristik biolimnologi dari suatu perairan.

Suatu penelitian terhadap Waduk Wadaslintang perlu dilakukan dengan tujuan untuk mendapatkan informasi dan data dukung yang diperlukan untuk menentukan lokasi reservat bagi perairan tersebut di atas. Pemilihan lokasi reservat itu pada gilirannya akan sangat bermanfaat bagi pengelolaan sumber daya perikanan di waduk tersebut.

\section{BAHAN DAN METODE}

Penelitian dilakukan dengan menggunakan metode survei yang meliputi survei kualitas air, biologi dan dinamika populasi ikan. Penelitian dilaksanakan pada bulan Juli, Agustus, September, November 1993 dan Januari 1994.

Studi ekologi perairan mencakup pengamatan beberapa parameter fisikakimia air, plankton dan tumbuhan air yang dilakukan di sekitar daerah Dam, Desa Kemejing, Pesanggrahan, Brug dan Sumbersari. Data aspek biologi (reproduksi dan kebiasaan makan) serta dinamika populasi ikan dikumpulkan dari contoh-contoh yang diambil dari hasil tangkapan nelayan maupun dari hasil penangkapan sendiri memakai jaring insang. Analisis contoh biolimnologi perairan dilakukan baik in situ maupun di Laboratorium Instalasi Penelitian Perikanan Air Tawar Jatiluhur. Analisis preferensi makanan ikan dilakukan memakai analisis "nodul" yaitu dengan menerapkan konsep "kemantapan" dan "fidelitas" (Murphy and Edwards, 1982).

\section{HASIL DAN PEMBAHASAN}

Pada umumnya, berdasarkan parameter fisika-kimia seperti suhu air, $\mathrm{pH}$, $\mathrm{CO}_{2}, \mathrm{O}_{2}, \mathrm{BOD}, \mathrm{DHL}$, turbiditas dan kecerahan, perairan yang diamati menunjukkan kisaran nilai yang cukup baik bagi kehidupan ikan dan biota akuatik lainnya (Table 1). Nilai-nilai tersebut masih baik hingga pada kedalaman $15 \mathrm{~m}$. Jadi berdasarkan kondisi kualitas airnya, maka daerah Kemejing, Pesanggrahan dan Brug layak untuk ditetapkan sebagai calon daerah reservat. Hasil pengukuran produktivitas primer menunjukkan bahwa tingkat kesuburan waduk ini tergolong rendah (oligotrofik), dan nilai tertinggi diperoleh di daerah Brug sedangkan yang terendah di sekitar Dam (Table 1).

Komposisi plankton di Waduk Wadaslintang terdiri dari tiga famili fitoplankton dan satu famili zooplankton (Table 2).

Fitoplankton yang dominan adalah famili Chlorophyceac. Dibanding dengan waduk-waduk yang lain di Pulau Jawa (Krismono et al., 1987; Kartami- 
Purnomo, K.; Kartamihardja, E.S. dan Satria, $H$.

hardja, 1992; Umar, 1991) ternyata kelimpahan plankton di Waduk Wadaslintang lebih rendah, hal ini erat kaitannya dengan usia waduk yang relatif masih muda. Hasil analisis struktur komunitas fitoplankton memakai indeks keragaman (H') dari Shannon-Wiever (Southwood, 1978) menunjukkan kisaran nilai antara 1.60-2.18 (Figure 1).

Table 1. Water quality of Wadaslintang reservoir

\begin{tabular}{|c|c|c|c|c|c|c|}
\hline \multirow{2}{*}{\multicolumn{2}{|c|}{ Paremeter }} & \multicolumn{5}{|c|}{ Location } \\
\hline & & \multirow{2}{*}{$\frac{D \subset m}{246.0}$} & \multirow{2}{*}{$\frac{\text { Kemejing }}{230.0}$} & \multirow{2}{*}{$\frac{\text { Pesanggraban }}{206.0}$} & \multirow{2}{*}{$\frac{B r * g}{178.0}$} & \multirow{2}{*}{$\frac{\text { Sumberseri }}{159.0}$} \\
\hline Transparency & $(\mathrm{Cm})$ & & & & & \\
\hline Temperature & $\rho C)$ & $26.5-29.5$ & $29.0-30.2$ & $30.0-31.0$ & $28.0-30.0$ & $27.0-30.0$ \\
\hline$p H$ & & 7.3-7.6 & $7.1-7.2$ & 7.0 & 7.0 & $7.4-7.7$ \\
\hline Conductivity & $105 / \mathrm{cm})$ & $123.0-132.0$ & $241.0-252.0$ & $251.0-269.0$ & $125.0-136.0$ & $121.0-135.0$ \\
\hline \multicolumn{2}{|c|}{ Tot. Alkalinity (mgCaCO$/ 3)$} & $23.1-48.3$ & $42.0-48.3$ & $65.0-89.0$ & $37.0-42.0$ & $23.1-54.6$ \\
\hline $\mathrm{CO}_{2}$ & $(m g / l)$ & $1.0-6.0$ & $\cdot$ & $0.0-2.0$ & $1.0-4.0$ & $2.0-8.0$ \\
\hline DO & $(m g / l)$ & 3.7 .5 .7 & 4.3-5.3 & $5.0-7.0$ & $3.0-6.0$ & $3.0-6.4$ \\
\hline$B O D$ & $(m g / l)$ & $0.3-2.4$ & $\cdot$ & $0.5-1.2$ & $\cdot$ & $1.4-1.7$ \\
\hline N-Total & $(m g / l)$ & $0.0-3.1$ & 2.9-3.8 & $2.6-3.7$ & $0.0 \cdot 2.1$ & $0.0-5.2$ \\
\hline PO4 & $(m g / l)$ & $0.2-0.8$ & $0.2-0.3$ & $0.2-0.6$ & $0.0-0.5$ & $0.3-1.2$ \\
\hline $\mathrm{Ca}$ & $(m g / l)$ & $46.0-63.0$ & $\cdot$ & $78.0-92.0$ & $12.0-40.0$ & 26.0 .42 .0 \\
\hline Turbidity & $(m g / l)$ & $140.0-412.0$ & $\cdot$ & $392.0-550.0$ & 615.0 .940 .0 & $350.0-360.0$ \\
\hline Total Dissolved solid & $(m g / l)$ & $100.0-107.0$ & $\cdot$ & 524.0 .559 .0 & $866.0-961.0$ & $850.0-862.0$ \\
\hline $\begin{array}{l}\text { Primary productivity } \\
\text { (mgC/s }\end{array}$ & $\left.n^{3} / j a m\right)$ & $5.8-12.5$ & $11.4-28.4$ & $23.5-47.0$ & $25.0-62.0$ & $15.6-65.0$ \\
\hline
\end{tabular}

Berdasarkan kriteria status mutu biologi perairan yang dikemukakan oleh Wilhm (1975), mutu lingkungan perairan waduk ini masih cukup baik sebab nilainya berkisar antara 1-3. Dari gambar (Figure 1) tersebut ternyata kondisi perairan calon reservat di daerah Pesanggrahan lebih baik dibanding daerah yang lain.

Waduk Wadaslintang relatif dapat dikatakan masih bersih dari invasi tumbuhan air. Hydrilla verticillata dan Myriophyllum spp. banyak dijumpai di pesisir pantai yang merupakan daerah perburuan udang bagi masyarakat sekitarnya. Jenis tumbuhan air lain yang perlu mendapat perhatian karena berbahaya adalah Eichbornia crassipes (eceng gondok), Salvinia molesta (kiambang), Pistia stratiotes (apu-apu) dan Monochoria sp. (wewean) yang kini hanya ditemukan di daerah pemasukan air dalam jumlah yang relatif masih sedikit. 


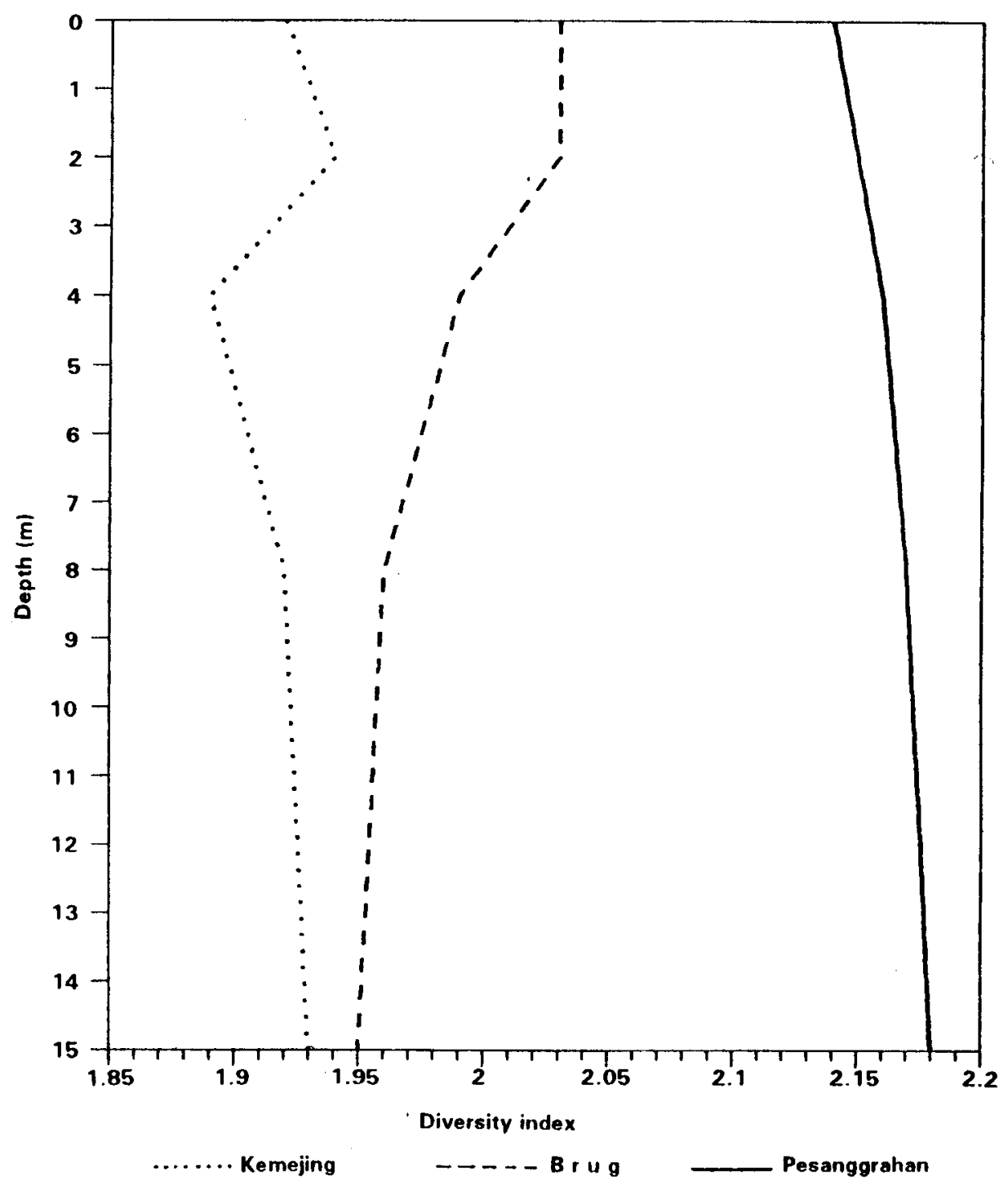

Figure 1. Diversity index of pbytoplankton in Wadaslintang reservoir

Waduk Wadaslintang dihuni oleh 14 jenis ikan (Table 3). Jenis-jenis ikan yang dominan ialah bader, tawes, palung, beong, kutuk dan brek. Ikan mola, mas dan nila merupakan jenis-jenis ikan introduksi.

Populasi ikan predator lebih sedikit dibanding ikan non predator sehingga komposisinya tidak seimbang. Introduksi ikan untuk perbaikan populasinya tidak perlu dilakukan, akan tetapi penebaran ikan menggunakan jenis ikan asli, 
Purnomo, K.; Kartamibardja, E.S. dan Satria, $H$.

Table 2. Composition and density of plankton in Wadaslintang reservoir

\begin{tabular}{|c|c|c|}
\hline Family & Genera & $\begin{array}{l}\text { Densily } \\
\text { (ind. } / \text { ) }\end{array}$ \\
\hline \multirow[t]{8}{*}{ Cblorophyceae } & Palmella & $18-144$ \\
\hline & Pediastrum & 90 \\
\hline & Staurastrum & $36-108$ \\
\hline & Closterium & $54-108$ \\
\hline & Desmidium & $18-162$ \\
\hline & Zygnema & $54-216$ \\
\hline & Ulotryx & $36-126$ \\
\hline & Pinularia & $18-126$ \\
\hline \multirow[t]{4}{*}{ Cyanopbyceae } & Anabaena & $36-108$ \\
\hline & Oscillatoria & $72-126$ \\
\hline & Rivularia & $54-144$ \\
\hline & Cylindrospermum & $18-72$ \\
\hline \multirow[t]{6}{*}{ Bacillariophyceae } & Navicula & $36-126$ \\
\hline & Synedra & $36-72$ \\
\hline & Diatoma & $54-162$ \\
\hline & Surirella & $18-126$ \\
\hline & Melosira & $72-126$ \\
\hline & Tabellaria & $36-90$ \\
\hline \multirow[t]{5}{*}{ Protozoa } & Peridinium & $36-162$ \\
\hline & Trinema & $18-54$ \\
\hline & Keratella & $18-126$ \\
\hline & Notbolca & $18-54$ \\
\hline & Ceratium & $36 \cdot 144$ \\
\hline
\end{tabular}

seperti tawes dan bader, diperlukan untuk menambah laju peremajaan populasi ikan. Musim pemijahan kebanyakan jenis ikan diduga terjadi antara bulan Desember sampai Januari, sebab pada bulan Nopember telah mencapai tahap matang gonad. Ikan-ikan yang matang gonad banyak ditemukan di daerah Pesanggrahan dan Brug. Hasil tangkapan ikan di Waduk Wadaslintang berkisar antara 11,0-19,7 kg per bulan atau 185 ton per tahun. Ukuran mata jaring insang yang dipakai nelayan kebanyakan lebih besar dari $5 \mathrm{~cm}$. Hasil analisis preferensi makanan berbagai jenis ikan tersebut menunjukkan bahwa jenis-jenis ikan pemanfaat makanan alami yang berupa tumbuhan, fitoplankton dan detritus berpeluang untuk dapat berkembang (Figure 2).

Pemilihan daerah reservat ditentukan berdasarkan kriteria dan skor seperti yang tertera pada Table 4. Daerah Dam dan Sumbersari tidak dapat ditetapkan sebagai daerah reservat sebab merupakan daerah bahaya dan pelabuhan tempat 
Table 3. Fish species inbabiting Wadaslintang reservoir

\begin{tabular}{lc}
\hline \multicolumn{1}{c}{ Fisb species } & Feeding babit \\
\hline Hampala macrolepidota (palung) & Karnivora \\
Barbodes gonionotus (tawes) & Herbivora \\
Barbodes balleroides (bader) & Herbivora \\
Puntius sp. (brek) & Herbivora \\
Mystus nemurus (baung) & Karnivora \\
Osteochilus basselti (nilem) & Planktivora \\
Mastacembelus erytbrotaenia (sili) & Karnivora \\
Mystacoleucus marginatus (wader) & Planktivora \\
Rasbora sp. (wader cakul) & Planktivora \\
Oreochromis niloticus (nila) & Omnivora \\
Cyprinus carpio (karper) & Omnivora \\
Clarias batracbus (lele) & Karnivora \\
Hypoptbalmicbtbys molitrix (mola) & Planktivora \\
Channa striata (kutuk) & Karnivora \\
\hline
\end{tabular}

() local name

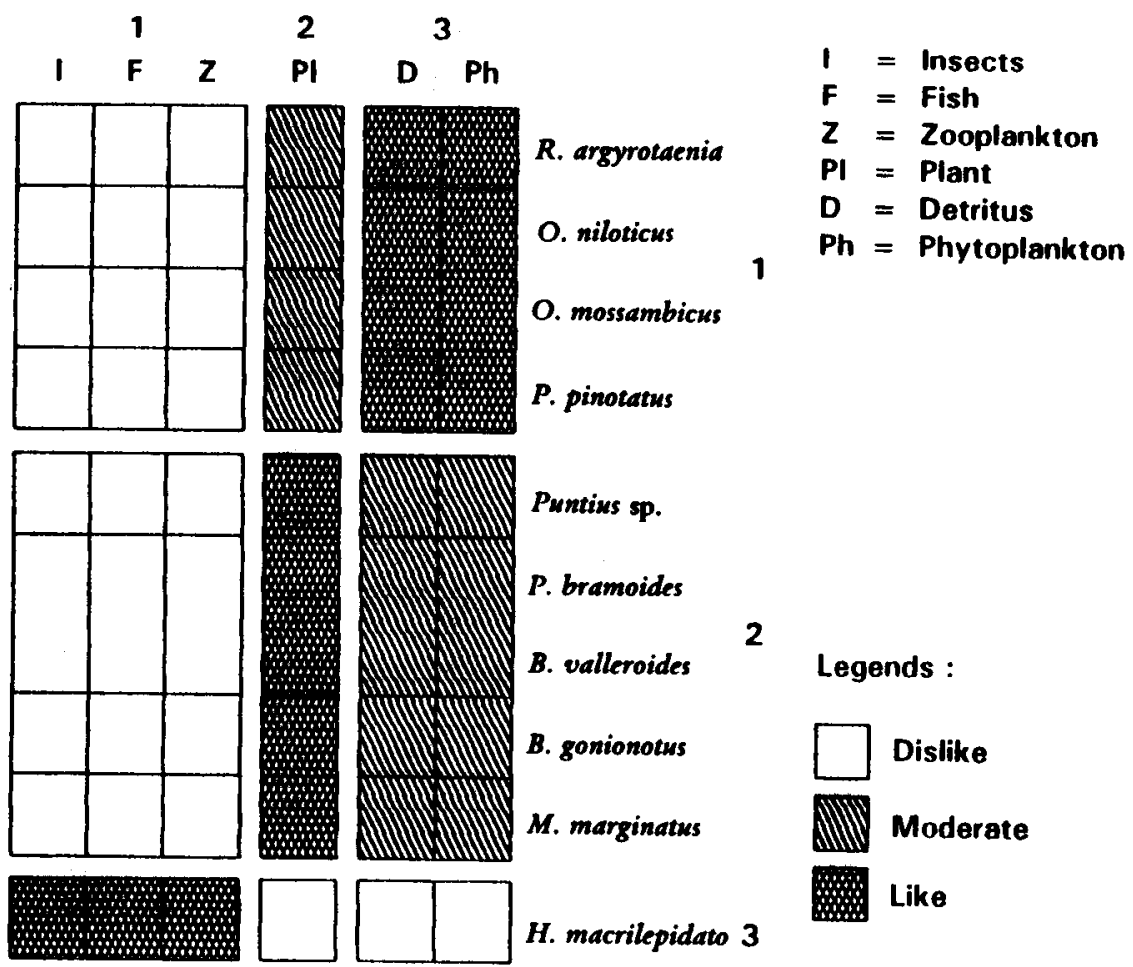

Figure 2. Food preferency of fishes in Wadaslintang reservoir 
Purnomo, K.; Kartamihardja, E.S. dan Satria, $H$.

Table 4. Criteria for determination of fisbery conservation areas of Wadaslintang reservoir based on suitability scores

\begin{tabular}{llll}
\hline \multicolumn{1}{c}{ Criteria } & \multicolumn{1}{c}{ Score $=1$} & \multicolumn{1}{c}{ Score $=2$} & \multicolumn{1}{c}{ Score $=3$} \\
\hline Area & Total $<5 \mathrm{ba}$, & Total $5-10 \mathrm{ha}$, & Total $>10 \mathrm{ba}$, \\
& Surface area & Surface area & Surface area during \\
& during low tide $<$ & during low tide & low tide $>60 \%$ \\
& $30 \%$ & $30-50 \%$ & \\
Fish diversity & Small & Moderate & High \\
Relative abundance & Small & Moderate & High \\
Spawning ground & Unimportant fishes & Dominant fishes & Specific fishes \\
Water quality & Poor & Moderate & Good \\
Aquatic biol. quality & Poor & Moderate & Good \\
Security & Poor & Moderate & Good \\
\hline
\end{tabular}

Note: $\quad$ Score $=3$ is the most suitable site for conservation area, score $=2$ is less suitable and score $=1$ is the least.

penyeberangan bagi masyarakat di sekitarnya. Oleh karena itu, penilaian calon reservat dilakukan terhadap daerah Brug, Pesanggrahan dan Kemejing (Table 5). Hasilnya menunjukkan bahwa skor masing-masing daerah hampir sama, namun daerah Pesanggrahan adalah yang tertinggi. Daerah Brug dan Kemejing cukup padat dengan perahu dan dekat pemukiman sehingga calon reservat yang paling baik adalah daerah Pesanggrahan.

Table 5. Scores of each potential site for fishery conservation areas in Wadaslintang reservoir

\begin{tabular}{lccc}
\hline \multirow{2}{*}{ Criteria } & \multicolumn{3}{c}{ Potential sites for fisbery conservation areas } \\
\cline { 2 - 4 } & Brug & Kemejing & Pesanggraban \\
\hline Area & 3 & 3 & 3 \\
Fish diversity & 3 & 3 & 2 \\
Relative abundance & 3 & 2 & 3 \\
Spawning ground & 3 & 2 & 3 \\
Water quality & 2 & 3 & 3 \\
Aquatic biology quality & 2 & 1 & 3 \\
Security & 2 & 2 & 3 \\
\hline Total scores & 18 & 16 & 20 \\
\hline
\end{tabular}




\section{KESIMPULAN DAN SARAN}

Untuk menjaga kelestarian produksi dan sumber daya perikanan di waduk Wadaslintang maka pengadaan daerah reservat mutlak diperlukan, terutama sebagai penghasil benih ikan secara alami. Daerah yang sesuai untuk reservat adalah Pesanggrahan di samping daerah lain yang masih memerlukan pertimbangan lebih lanjut, yaitu daerah Brug dan Kemejing.

Agar reservat itu dapat berfungsi secara baik maka harus dipantau dan dikelola secara baik, misalnya daerah reservat diberi rambu-rambu yang jelas dan dilakukan penyuluhan kepada para nelayan agar tumbuh rasa memiliki dan tanggung jawab. Kebijakan pengelolaan tersebut sebaiknya dituangkan dalam bentuk Peraturan Daerah sehingga sangsinya jelas. Untuk ini diperlukan dukungan hasil penelitian tentang teknologi pengelolaan daerah reservat.

\section{DAFTAR PUSTAKa}

Bhukaswan, T. 1980. Management of Asian Reservoir Fisheries. FAO Fish. Tech. Pap. (207). 69p.

Kartamihardja, E.S. 1992. Beberapa aspek bio-limnologi dan pengelolaan perikanan di Waduk Wadaslintang, Wonosobo, Jawa Tengah. Bull. Penel. Perik. Darat. 11(1): 1-11.

Krismono, D.W.H. Tjahjo, A. Hardjamulia, S. Nuroniah dan C. Umar. 1987. Penelitian limnobiologis Waduk Saguling pada tahap post inundasi. Bull. Penel. Perik. Darat. Edisi Khusus. 6(3): 1-31.

Murphy, P.M. and R.W. Edwards. 1982. The spatial distributions of the freshwater macroinvertebrate fauna of the river Ely, South Wales, in relation to pollutional discharges. Env. Poll., 29:111-124.

Southwood, T.R.E. 1978. Ecological methods. With particular reference to the study of insect populations. Chapman and Hall. 523p.

Umar. C. 1991. Distribusi plankton di Waduk Cirata, Jawa Barat pada tahun 1988-1989. Bull. Penel. Perik. Darat. 10(1): 1-9.

Wilhm, J.F. 1975. Biological indicators of pollution. In B.A. Whitton, ed. River ecology. Blackwell Sci. Publ.: 375-402 